\title{
AVALIAÇÃO DO COMPORTAMENTO ANÔMALO DE ANOCENTOR NITENS (NEUMANN) (ACARI: IXODIDAE), DURANTE A FASE NÃO PARASITÁRIA
}

\author{
Nicolau Maués da Serra-Freire ${ }^{1}$ \\ Silvia Maria Mendes Ahid ${ }^{2}$
}

\begin{abstract}
AVALIATION OF THE ANOMALOUS BEHAVIOR OF ANOCENTOR NITENS (NEUMANN) (ACARI: IXODIDAE), DURING THE NON PARASITIC PHASE. A new technique was develop to study the anomalous behavior of non parasitic phase of Anocentor nitens on horse host. From the total teleogines was still alive during all experimental period, $89.1 \%$ laided eggs on ear host. The eclosion index was $77.05 \%$ with $80.0 \%$ of eclodibility. The preoviposition period and oviposition period was 3 to 17 days (4.92 0.73 days) and 16 to 41 days (24.38 \pm 1.05 days), respectively. The incubation period was 26 to 48 days (34.94 \pm 2.92 days). It was confirmed that $\mathbf{A}$. nitens teleogine could laid on ear of horse, when it was dettachment and a factor impossibilited it down on ground.

KEY WORDS. Acari, Ixodidae, Anocentor nitens
\end{abstract}

Anocentor nitens (Neumann, 1897) tem distribuição quase restrita nas regiões neotropicais. No Brasil foi descrito da Bahia, Pará, Mato Grosso do Sul, São Paulo, Paraná, Minas Gerais, Rio de Janeiro e Pernambuco (DA ROCHA, 1986; SERRA-FREIRE, 1987).

Comprovadamente $A$. nitens não possui especificidade em relação ao hospedeiro (MORENO, 1984; SERRA-FREIRE \& MIZIARA, 1989), tendo sido incriminado parasitando diferentes mamíferos domésticos (FLECHTMANN, 1985) e animais silvestres (ARAGÃO \& FONSECA, 1953; FORRESTER et al., 1985). O mesmo pode ser dito em relação ao local de fixação (SERRA-FREIRE, 1987).

Influenciado pelo hospedeiro, $A$. nitens apresenta melhor desempenho heteroxeno quando o hospedeiro é bovino em relação ao coelho como hospedeiro (SERRA-FREIRE \& MIZIARA, 1989). Em ciclo monoxeno, no entanto, pode ser visto formando colônias no pavilhão auricular, com diferentes estádios evolutivos (DUNN, 1915), embora com índices biológicos distintos de acordo com a origem da cepa (DAEMON \& SERRA-FREIRE, 1987).

SERRA-FREIRE (1987), em infestações naturais em equinos, observou teleóginas realizando postura no local onde haviam ingurgitado e uma que-

1) Departamento de Parasitologia Veterinária, Universidade Federal Rural do Rio de Janeiro, 23851-970 Itaguaí, Rio de Janeiro, Brasil.

2) Universidade Estadual do Maranhão, Maranhão, Brasil. 
nógina morta, caracterizando um comportamento incomum para a espécie $A$. nitens. O presente trabalho, visou elucidar, sob condições experimentais, o comportamento anômalo do $A$. nitens na fase de teleógina e nas diferentes etapas biológicas da fase não parasitária.

\section{MATERIAL E MÉTODOS}

Utilizou-se dez equinos pertencentes ao Curso de Pós-Graduação em Parasitologia Veterinária da Universidade Federal Rural do Rio de Janeiro. Todos já haviam tido contactos com carrapatos. Durante o experimento estiveram sob regime semi-extensivo, sem alteração de suas rotinas de trabalho na Estação para Pesquisas Parasitológicas W.O. Neitz, EPPWON/CPGPV. No dia anterior ao início do experimento, fez-se tricotomia na face interna dos pavilhões auriculares e os equinos foram vestidos com uma máscara de brim onde se prendiam os cones de pano alvejado protetores dos pavilhões.

Teleóginas de $A$. nitens de origem equina foram removidas manualmente e selecionadas segundo o tamanho, a cor do idiossoma e o peso, escolhendo-se as que tivessem peso igual ou superior ao da media aritmética do total das fêmeas coletadas $(X=175 \mathrm{mg})$. Em seguida, as teleóginas foram banhadas com solução antifúngica por 20 minutos, secas com papel absorvente e colocadas individualmente em envelopes de tecido de nylon com malha de $60 \mu \mathrm{m}$ medindo $2 \times 3 \mathrm{~cm}$ e lacrados por pressão de ferro quente nos bordos. Dois envelopes contendo teleóginas foram colocados por pavilhão auricular e ficaram protegidos pelos cones protetores. Teleóginas permaneceram desta forma até completar a postura. As posturas, após remoção das quenóginas, ficaram alojadas nos pavilhões auriculares encerradas nos envelopes até eclosão dos ovos com emergência de neolarvas ou serem consideradas inviáveis.

Seis dos equinos utilizados eram machos castrados e neles repetiu-se três vezes o procedimento metodológico. Nos outros quatro equinos, houve duas repetições; esse grupo era composto por um garanhão e tres fêmeas sexualmente ativas. Totalizou-se, durante a fase experimental, 104 teleóginas observadas para os seguintes parâmetros: período de pré-postura; período de postura; período de incubação e eclosão; número de teleóginas que realizaram postura; número de posturas que eclodiram e se houve fixação ou abandono do hospedeiro pelas neolarvas emergidas no pavilhão auricular.

\section{RESULTADOS E DISCUSSÃO}

Das 104 teleóginas, 28 morreram por esmagamento dentro dos envelopes nos pavilhões auriculares dos equinos. Outras oito foram extraviadas. É possível que o uso de cabrestos ou laços de cordas no trabalho diário dos animais e a remoção voluntária e brusca das máscaras pelos equinos quando confinados nos piquetes, tenham favorecido para estas perdas. Assim permaneceram no experimento 68 teleóginas $(65,38 \%)$ onde 61 realizaram postura no local onde haviam sido alojadas; 47 das posturas $(77,05 \%)$ chegaram a eclosão dos ovos 
com emergência das neolarvas no interior dos envelopes. A estimativa visual de eclodibilidade foi de $80 \%$ (60 - 100\%), o que está de acordo com DUNN (1915) e reflete as observações de DAEMON \& SERRA-FREIRE (1984). Para as 61 posturas o período de pré-postura variou de três a 17 dias $(4,92 \pm 0,73$ dias) e moda de cinco dias. Período de postura de 16 a 41 dias (24,38 $\pm 1,05$ dias), sendo o dia modal o $25^{\circ}$. Assinalou-se o aumento do tempo máximo desses períodos, inclusive superiores aos encontrados por DIAMANT \& STRICKLAND (1965) e ROMERO (1984).

O período de incubação contado para as 47 posturas que eclodiram foi de 26 a 48 dias, cuja média de 34,54 22,92 dias é similar a de OLIVER et al. (1987) que foi de 34 dias em condições de umidade relativa superior a $90 \%$. O período de eclosão de três a sete dias $(4,46+0,37$ dias $)$ não diferiu do encontrado por DAEMON \& SERRA-FREIRE (1984,1987), apesar dos autores terem trabalhado sob condições em estufa para BOD restringindo em muito o fotoperíodo para os breves momentos em que abriram a estufa e observavam os carrapatos.

A maior amplitude dos índices biológicos ora apresentados reflete a metodologia aplicada, onde promovia menor incidência de luz na área onde estavam as teleóginas e posturas nos envelopes. É possível que o arranjo das máscaras de brim com cones de pano alvejado como protetores dos pavilhões, e o tempo de exposição dos animais a céu aberto com aumento da umidade relativa no local pela maior sudorese e menor ventilação tenham permitido o fotoperíodo casual e provocado o aumento daqueles tempos. Conclui-se que as teleóginas impedidas de abandonarem o hospedeiros podem realizar postura no pavilhão auricular do equino reforçando o aspecto de ciclo monoxeno.

\section{REFERÊNCIAS BIBLIOGRÁFICAS}

ARAGÃO, H.B. \& F. FONSECA. 1953. Notas de Ixodologia. VIII. Otocentor nitens Neumann, 1897 versus Anocentor columbianus Schulze, 1873 e comentários sobre a rápida disseminação desse Ixodídeo no Brasil (Acari: Ixodidae). Mem. Inst. Oswaldo Cruz. 51: 309-501.

DAEMON, E. \& N.M. SERRA-FREIRE. 1984. Biologia de Anocentor nitens Neumann, 1897: Fase não parasitária em condições de laboratório. Rev. Bras. Med. Vet. 6 (6): 181-183.

—. Efeitos do parasitismo em bovinos sobre a biologia da fase não parasitária de Anocentor nitens (Neumann. 1897) (Acarina: Ixodidae). Rev. Brasil. Med. Vet. 9 (2): 42-47.

DA ROCHA, J.M. 1986. Identificação e incidência dos ixodídeos no município de Garanhuns - PE. Arq. Brasil. de Med. Vet. e Zoot. 38 (5): 813-818.

DIAMANT, G. \& R.K. STRICKLAND. 1965. Manual on livestock tick. U.S. Dept. Agric. Res. Serv. ARS. 91-49, 142p.

DUNN, L.H. 1915. Observations on the preoviposition, oviposition and incubation periods of Dermacentor nitens in Panamá (Arach., Acar.) Ent. News. 26: 214-219 
FLECHTMANN, C.H.W. 1985. Ácaros de Importância Médico Veterinária. São Paulo, Nobel, $3^{\text {a }}$ ed., 192p.

FORRESTER, D.; J.A. CONTI \& R.C. BELDEN. 1985. Parasites of the Florida Panther (Felis concolor coryi). Proc. Helminthol. Soc. Washington. 52 (1): 95-97.

MORENO, E.C. 1984. Incidência de ixodídeos em bovinos de leite e prevalência em animais domésticos da região metalúrgica de Minas Gerais. Tese de Mestrado, não publicada, Universidade Federal de Minas Gerais, Belo Horizonte, 105p.

OLIVER, JR., J.H.; M.R. OWSLEY \& H.J. HUTCHESON. 1987 Chromosomes of the tropical horse tick, Dermacentor nitens (Acari: Ixodidae) with notes on the life cycle. J. Parasitol. 73 (6): 1279-1280.

ROMERO, H.Q. 1984. Parasitologia y enfermidades parasitárias de animales domésticos. México, Limusa, 876p.

SERRA-FREIRE, N.M. 1987. Comportamento exótico de teleóginas de Anocentor nitens (Neumann, 1897) (Acarina: Ixodidae). Arq. Flum. Med. Vet. 2 (1): 17-18.

SERRA-FREIRE, N.M. \& S.R. MIZIARA. 1989. Influência do hospedeiro no ciclo heteroxeno de Anocentornitens (Neumann, 1897). Mem. Inst. Oswaldo Cruz 84 (supl. IV): 213-218.

Recebido em 28.I.1991; aceito em 25.XI.1994. 